\title{
Preface for the special issue on The Process of Explanation
}

\section{Guest Editors: Andrei Cimpian (New York University) and Frank Keil (Yale University)}

\author{
Andrei Cimpian ${ }^{1} \cdot$ Frank Keil $^{2}$
}

Published online: 22 September 2017

(C) Psychonomic Society, Inc. 2017

Explanations are crucial to our cognitive lives because they inform our understanding of the world, structure our concepts, and guide our actions. Yet the processes that underlie explanation remain largely unknown: How do people generate, evaluate, and use explanations? Answering this question is a major challenge because even a rough specification of the processes involved requires considering a wide range of issues in human cognition: It requires that we understand how explanatory processes access relevant facts in memory; how these processes extract explanation-relevant facts from the evidence in the environment; how implicit computations relevant to generating explanations interact with explicit, working-memorydependent processes; and so on. In other words, considering explanation as a process forces us to acknowledge and explore the multifaceted nature of this fundamental cognitive ability.

This special issue of Psychonomic Bulletin \& Review begins to tackle these complexities. The articles in it provide new, often surprising, insights into the processes involved in generating, evaluating, and using explanations. As a result, this collection of articles is a state-of-the-art tool for any scholar interested in understanding or studying explanation. To orient readers to the content of the special issue, we provide a brief overview of the themes that emerged from the articles.

Andrei Cimpian

andrei.cimpian@nyu.edu

Frank Keil

frank.keil@yale.edu

1 Department of Psychology, New York University, 6 Washington Place, New York, NY 10003, USA

2 Department of Psychology, Yale University, Box 208205, New Haven, CT 06520, USA
Several articles investigate the processes involved in generating explanations and illustrate how much our ability to generate explanations depends on other basic cognitive competencies. Hoyos and Gentner (2017), for example, examine how the process of comparing across - and analogizing from-previous experiences is involved in generating explanations. This theme is echoed by the work of Thibodeau, Crow, and Flusberg (2017), who demonstrate the power of explanations that illuminate one phenomenon by drawing an analogy with another. The centrality of comparison to explanation is also highlighted by Chin-Parker and Bradner's (2017) treatment of the ways in which generating explanations involves comparing the actual state of the world (e.g., cutting onions makes us cry) with similar, yet counterfactual, states (e.g., cutting tomatoes does not).

Three articles provide insight into the reciprocal relationship between explanation generation and memory retrieval. Using eye-tracking data, Scholz, Krems, and Jahn (2017) are able to reconstruct how memory retrieval shapes the course of explanation generation on a moment-by-moment basis. Rindal, Chrobak, Zaragoza, and Weihing (2017) and Soares and Storm (2017) examine the other side of the coin - the effect of generating explanations on subsequent memory for the phenomena being explained. Their experiments suggest, for example, that people's spontaneous tendency to use new information to make sense of previously experienced events "rewrites" these events in memory and may thus lead to unreliable eyewitness testimony (Rindal et al.).

A second major focus of the special issue is on the processes that shape how people evaluate explanations. For instance, Vasilyeva, Wilkenfeld, and Lombrozo (2017) demonstrate that explanations are evaluated in part based on their usefulness to the reasoner: Explanations that support ongoing activities are judged to be better. Bechlivanidis, Lagnado, Zemla, and Sloman (2017) investigate the role that the abstraction 
(versus concreteness) of an explanation plays in its evaluation, finding that concrete explanations are often preferred, as long as they manage to clearly communicate the key properties that caused the explanandum to occur. Mills, Danovitch, Rowles, and Campbell (2017) examine the development of children's ability to evaluate explanations, with a particular focus on the ability to detect empty, circular explanations. Prasada (2017) provides a compelling account of the circumstances under which people judge formal explanations (that is, explanations that attribute an individual's features and behavior to the kind to which it belongs) to be appropriate. Finally, Zemla, Sloman, Bechlivanidis, and Lagnado (2017) use a corpus of everyday explanations to examine whether a whole host of previously hypothesized explanatory "virtues" (simplicity, coherence, etc.) actually predict how people evaluate explanations. One of the more surprising claims of their work is that people often prefer complex explanations that invoke multiple causal mechanisms over simpler explanations.

A third key theme of the special issue explores the downstream consequences of explaining. For instance, explanations are an essential element of learning, and Rittle-Johnson and Loehr (2017) provide a timely review of the usefulness (and limits) of eliciting explanations as a learning tool in the classroom. The experiments reported by Baillargeon and DeJong (2017) suggest that even infants use explanatory inferences to guide their learning about the physical world. Similarly, Taborda-Osorio and Cheries (2017) argue that children's learning about the biological world is shaped by powerful explanatory biases that emerge as early as infancy. The aforementioned work by Mills et al. (2017) also highlights how children's explanations guide their learning: The more sensitive children were to the emptiness of an explanation, the more curious they remained about the phenomenon in question. We see a downstream effect of children's explanations in the studies by Walker, Bonawitz, and Lombrozo (2017) as well. They show that the process of generating explanations leads children to use the "virtues" of explanations (simplicity, in particular) as a guide in their subsequent causal predictions. Legare, Sobel, and Callanan (2017) make the case that the link between explanation and learning is best understood by taking into account the sociocultural context. In childhood and beyond, explanations - and the learning they facilitate - are a collaborative process shaped by the cultural norms of one's community. Although we have so far focused on the link between explanations and learning, the consequences of generating and adopting explanations are much broader. Notably, Weisman and Markman (2017) argue for explanation as a tool for health interventions. Clear explanations revealing the causal link between a behavior and a health outcome can be an effective means of inducing behavior change.

Finally, the articles in this special issue highlight the ubiquity - indeed, inescapability - of explanations in our mental lives. For example, Gantman, Adriaanse, Gollwitzer, and Oettingen (2017) review research suggesting that people are so driven to explain that they explain (or rather confabulate about) the unexplainable: behaviors activated nonconsciously, which are completely inaccessible to introspection. Similarly, Shtulman and Morgan (2017) show that people unwittingly apply the causal-explanatory frameworks they use in everyday life to phenomena that fall outside their scope (e.g., impossible events, such as levitating objects). The same overconfidence in the power of explanation is documented by Woolley and Cornelius (2017), who also provide a detailed analysis of the development of explanations for mundane, improbable, and extraordinary events.

With its diversity of perspectives and approaches, this special issue makes a unique contribution to the psychology of explanation. Research in this issue should inspire curiosity among a broad spectrum of scientists and spark a new wave of research on this foundational, but still underexplored, cognitive ability.

\section{References}

Baillargeon, R., \& DeJong, G. F. (2017). Explanation-based learning in infancy. Psychonomic Bulletin \& Review. https://oi.org/10.3758/ s13423-017-1334-4

Bechlivanidis, C., Lagnado, D. A., Zemla, J. C., \& Sloman, S. (2017). Concreteness and abstraction in everyday explanation. Psychonomic Bulletin \& Review. https://doi.org/10.3758/s13423-017-1299-3

Chin-Parker, S., \& Bradner, A. (2017). A contrastive account of explanation generation. Psychonomic Bulletin \& Review. https://doi.org/10. 3758/s13423-017-1349-x

Gantman, A. P., Adriaanse, M. A., Gollwitzer, P. M., \& Oettingen, G. (2017). Why did I do that? Explaining actions activated outside of awareness. Psychonomic Bulletin \& Review. https://doi.org/10. 3758/s13423-017-1260-5

Hoyos, C., \& Gentner, D. (2017). Generating explanations via analogical comparison. Psychonomic Bulletin \& Review. https://doi.org/10. 3758/s13423-017-1289-5

Legare, C. H., Sobel, D. M., \& Callanan, M. (2017). Causal learning is collaborative: Examining explanation and exploration in social contexts. Psychonomic Bulletin \& Review. https://doi.org/10.3758/ s13423-017-1351-3

Mills, C. M., Danovitch, J. H., Rowles, S. P., \& Campbell, I. L. (2017). Children's success at detecting circular explanations and their interest in future learning. Psychonomic Bulletin \& Review. https://doi. org/10.3758/s13423-016-1195-2

Prasada, S. (2017). The scope of formal explanation. Psychonomic Bulletin \& Review. https://doi.org/10.3758/s13423-017-1276-x

Rindal, E. J., Chrobak, Q. M., Zaragoza, M. S., \& Weihing, C. A. (2017). Mechanisms of eyewitness suggestibility: Tests of the explanatory role hypothesis. Psychonomic Bulletin \& Review. https://doi.org/10. 3758/s13423-016-1201-8

Rittle-Johnson, B., \& Loehr, A. M. (2017). Eliciting explanations: Constraints on when self-explanation aids learning. Psychonomic Bulletin \& Review. https://doi.org/10.3758/s13423-016-1079-5

Scholz, A., Krems, J. F., \& Jahn, G. (2017). Watching diagnoses develop: Eye movements reveal symptom processing during diagnostic reasoning. Psychonomic Bulletin \& Review. https://doi.org/10.3758/ s13423-017-1294-8 
Shtulman, A., \& Morgan, C. (2017). The explanatory structure of unexplainable events: Causal constraints on magical reasoning. Psychonomic Bulletin \& Review. https://doi.org/10.3758/s13423-016-1206-3

Soares, J. S., \& Storm, B. C. (2017). Explanation can cause forgetting: Memory dynamics in the generation of new arguments. Psychonomic Bulletin \& Review. https://doi.org/10.3758/s13423-017-1283-y

Taborda-Osorio, H., \& Cheries, E. W. (2017). Developmental origins of biological explanations: The case of infants' internal property bias. Psychonomic Bulletin \& Review. https://doi.org/10.3758/s13423017-1350-4

Thibodeau, P. H., Crow, L., \& Flusberg, S. J. (2017). The metaphor police: A case study of the role of metaphor in explanation. Psychonomic Bulletin \& Review. https://doi.org/10.3758/s13423-016-1192-5

Vasilyeva, N., Wilkenfeld, D., \& Lombrozo, T. (2017). Contextual utility affects the perceived quality of explanations. Psychonomic Bulletin \& Review. https://doi.org/10.3758/s13423-017-1275-y
Walker, C. M., Bonawitz, E., \& Lombrozo, T. (2017). Effects of explaining on children's preference for simpler hypotheses. Psychonomic Bulletin \& Review. https://doi.org/10.3758/s13423016-1144-0

Weisman, K., \& Markman, E. M. (2017). Theory-based explanation as intervention. Psychonomic Bulletin \& Review. https://doi.org/10. 3758/s13423-016-1207-2

Woolley, J. D., \& Cornelius, C. A. (2017). Wondering how: Children's and adults' explanations for mundane, improbable, and extraordinary events. Psychonomic Bulletin \& Review. https://doi.org/10. 3758/s13423-016-1127-1

Zemla, J. C., Sloman, S., Bechlivanidis, C., \& Lagnado, D. A. (2017). Evaluating everyday explanations. Psychonomic Bulletin \& Review. https://doi.org/10.3758/s13423-017-1258-z 